\title{
Rancang Bangun Sistem Informasi Data Kebudayaan Pada Instansi Pemerintahan Menggunakan Framework CodeIgniter
}

\author{
Giandari Maulani ${ }^{1}$, Muhamad Yusup ${ }^{2}$, Amarulloh $^{3}$ \\ ${ }^{1,3}$ Program Studi Sistem InformasiUniversitas Raharja, \\ ${ }^{2}$ Program Studi Manajemen Retail Universitas Raharja \\ E-mail: "
}

\begin{abstract}
Abstrak
Penelitian ini dibuat dengan tujuan untuk membangun sistem informasi untuk pengolahan datadata kebudayaan yang ada pada instansi pemerintahan. Studi kasus penelitian ini pada instansi pemerintahan khusus wilayah Tangerang, tepatnya pada Disporabudpar (Dinas Pemuda, Olahraga, Kebudayaan dan Pariwisata) Kabupaten Tangerang. Dinas ini memiliki tugas-tugas penting yaitu mempersiapkan kebijakan, koordinasi, pembinaan dan pengendalian pada bidang Kebudayaan. Dalam menjalankan tugasnya, baik pada program-program maupun pada kegiatan kebudayaannya biasanya meliputi aktivitas penyusunan, pengumpulan dan penganalisaan data dan informasi. Untuk saat ini, instansi pemerintahan Disporabudpar kabupaten Tangerang ini belum memiliki sistem informasi yang terkomputerisasi di dalam pengelolaan data kebudayaannya dan belum adanya pemanfaatan sistem database mengenai data kebudayaan, sehingga dalam proses penyimpanan datanya masih manual dan masih belum efektif dari segi keamanannya. Data-data tersebut hanya disimpan pada tempat dokumen biasa, sehingga kurang optimal dan tidak efektif didalam proses pengolahan data kebudayaannya. Dalam penelitian ini menggunakan Framework CodeIgniter yang merupakan kerangka kerja PHP yang Powerful yang di-build dengan elegan untuk membuat aplikasi Web memiliki fitur yang lengkap. Untuk metode analisa, penelitian ini menerapkan metode PIECES (Performance, Information, Economy, Control, Efficiency dan Services) agar tercipta suatu rancang bangun sistem informasi yang lebih optimal di dalam menyajikan suatu data dan informasi, khususnya Data Kebudayaan pada instansi pemerintahan.
\end{abstract}

Kata Kunci : Sistem Informasi, Data Kebudayaan, Framework CodeIgniter, Analisa PIECES.

\begin{abstract}
This research was made with the aim of building an information system for processing cultural data in government agencies. The case study of this research is at a special government agency for the Tangerang area, to be precise at the Disporabudpar (Department of Youth, Sports, Culture and Tourism) Tangerang Regency. This service has important tasks, namely preparing policies, coordinating, fostering and controlling in the field of Culture. In carrying out their duties, both in programs and in cultural activities, they usually include the activities of compiling, collecting and analyzing data and information. For now, this Tangerang Regency Disporabudpar government agency does not yet have a computerized information system in managing cultural data and there is no use of a database system regarding cultural data, so that the data storage process is still manual and still not effective in terms of security. These data are only stored in ordinary documents, so they are less than optimal and ineffective in the processing of cultural data. In this study, the CodeIgniter Framework is used, which is a powerful PHP framework that is elegantly built to create a full-featured Web application. For the analytical method, this study applies the PIECES (Performance, Information, Economy, Control, Efficiency and Services) method in order to create a more optimal design of information systems in presenting data and information, especially Cultural Data in government agencies.
\end{abstract}


Keywords : Information Systems, Cultural Data, CodeIgniter Framework, PIECES Analysis.

\section{PENDAHULUAN}

Penelitian ini dibuat dengan tujuan untuk membangun sistem informasi untuk pengolahan data-data kebudayaan yang ada pada instansi pemerintahan. Studi kasus penelitian ini pada instansi pemerintahan khusus wilayah Tangerang, tepatnya pada Disporabudpar (Dinas Pemuda, Olahraga, Kebudayaan dan Pariwisata) Kabupaten Tangerang. Dinas ini memiliki tugas-tugas penting yaitu mempersiapkan kebijakan, koordinasi, pembinaan dan pengendalian pada bidang Kebudayaan. Dalam menjalankan tugasnya, baik pada program-program maupun pada kegiatan kebudayaannya biasanya meliputi aktivitas penyusunan, pengumpulan dan penganalisaan data dan informasi. Untuk saat ini, instansi pemerintahan Disporabudpar kabupaten Tangerang ini belum memiliki sistem informasi yang terkomputerisasi di dalam pengelolaan data kebudayaannya dan belum adanya pemanfaatan sistem database mengenai data kebudayaan, sehingga dalam proses penyimpanan datanya masih manual dan masih belum efektif dari segi keamanannya. Data-data tersebut hanya disimpan pada tempat dokumen biasa, sehingga kurang optimal dan tidak efektif didalam proses pengolahan data kebudayaannya. Dalam penelitian ini menggunakan Framework CodeIgniter yang merupakan kerangka kerja PHP yang Powerful yang di-build dengan elegan untuk membuat aplikasi Web memiliki fitur yang lengkap. Untuk metode analisa, penelitian ini menerapkan metode PIECES (Performance, Information, Economy, Control, Efficiency dan Services) agar tercipta suatu rancang bangun sistem informasi yang lebih optimal di dalam menyajikan suatu data dan informasi, khususnya Data Kebudayaan pada instansi pemerintahan.

\section{TINJAUAN PUSTAKA}

\section{Perancangan Sistem}

Menurut Sudaryono (2020:341), Rancang bangun Sistem merupakan tahap siklus system development yang dapat disebut sebagai tahap pendefinisian kebutuhan tentang hal yang fungsional dan juga menggambarkan bagaimana suatu sistem tersebut dibentuk. [1]

\section{Data}

Menurut Gunadi (2020:69), Data merupakan sesuatu yang perlu diolah lebih lanjut untuk dapat menghasilkan suatu informasi ataupun keterangan yang secara kualitatif dan kuantitatif menunjukkan Facs yang berguna dan bermanfaat serta dapat memberi gambaran mengenai kondisi suatu keadaan. [2]

\section{Kebudayaan}

Menurut Novitasari (2020:2), Kebudayaan merupakan Gabungan satu kesatuan yang terdiri dari gagasan, tindakan serta hasil karya manusia sehingga membentuk suatu sistem utuh dalam rangka menjalani kehidupan normal bermasyarakat serta sebagai manusia yang dapat berkembang dengan pembelajaran.[3]

\section{LITERATUR REVIEW}

1. Penelitian yang diambil sebagai literatur review dari Ruktami (2018), yang berjudul "Sistem Informasi Pengolahan Data Kebudayaan Minangkabau Berbasis Web". Dalam penelitiannya tersebut dijelaskan bahwa pengolahan data kebudayaan minangkabau saat itu masih manual menggunakan pencatatan buku dan hal ini menyebabkan pekerjaan menjadi kurang efisien serta membutuhkan waktu yang lama khususnya saat Data Searching. Penelitian ini kemudian membuat aplikasi berbasis web yang dapat memberikan informasi mengenai Data Kebudayaan Minangkabau secara cepat dengan tampilan grafis yang sangat bagus. [4] 
2. Penelitian yang diambil sebagai literatur review dari Christian (2018), yang berjudul "Perancangan Sistem Informasi Website Seni Budaya Kota Prabumulih Pada Dinas Pendidikan Dan Kebudayaan Kota Prabumulih". Tujuan penelitiannya untuk Re-Promote Seni Budaya dari kota Prabumulih yang menarik untuk disajikan kepada masyarakat. Penelitian ini juga menghasilkan Web yang berisi informasi lengkap mengenai apa saja yang menjadi Seni Budaya kota Prabumulih dengan segala kelebihannya.[5]

3. Penelitian yang diambil sebagai literatur review dari Manuho (2018), yang berjudul "Aplikasi Sistem Informasi E-Culture Kabupaten Sitaro Berbasis Web". Tujuan penelitiannya untuk memberikan informasi mengenai kebudayaan yang dimiliki oleh Kabupaten Sitaro yang unik. Penelitian ini dibuat dengan berbasis Web agar kebudayaan kabupaten Sitaro dapat dikenal oleh masyarakat luas.[6]

\section{METODE PENELITIAN}

Metode Penelitian dalam penelitian rancang bangun sistem informasi data kebudayaan pada instansi pemerintahan menggunakan Framework CodeIgniter ini terdiri dari :

\subsection{Metode Pengumpulan Data}

Secara umum metode pengumpulan data itu biasanya berupa pengamatan/observasi, wawancara dan studi pustaka, begitupun pada penelitian ini, dengan penjelasan sebagai berikut :

\section{a. Observasi}

Observasi penelitian ini dilakukan pada instansi pemerintahan, tepatnya pada Disporabudpar Kabupaten Tangerang.

\section{b. Wawancara}

Wawancara untuk penelitian ini dilakukan kepada Stakeholder Ibu Hj. Nurbaeti, SE, MM sebagai subjek sumber data pendukung penelitian.

\section{c. Studi Pustaka}

Studi pustaka pada penelitian ini bersumber dari jurnal-jurnal nasional terakreditasi sehingga membuat penelitian ini memiliki banyak referensi.

\subsection{Metode Analisa Sistem}

Metode analisa PIECES merupakan metode analisa yang dipilih pada penelitian ini dan akan dijabarkan pada tabel berikut :

Tabel 1. Metode Analisa PIECES

\begin{tabular}{|c|l|l|}
\hline Indikator & \multicolumn{1}{|c|}{ Sistem Berjalan } & \multicolumn{1}{c|}{ Sistem Usulan } \\
\hline \multirow{5}{*}{ Performance } & $\begin{array}{l}\text { Sistem yang berjalan saat ini terkait } \\
\text { pengolahan data kebudayaannya } \\
\text { masih manual sehinga } \\
\text { memerlukan waktu yang cukup } \\
\text { lama. }\end{array}$ & $\begin{array}{l}\text { Sistem yang diusulkan yaitu berupa } \\
\text { sistem berbasis Web dengan baik yang } \\
\text { dapat mengelola proses pendataannya, } \\
\text { sehingga dapat mempersingkat waktu. }\end{array}$ \\
\hline \multirow{5}{*}{ Information } & $\begin{array}{l}\text { masih adanya Human Error, yang } \\
\text { menyebabkan informasi yang } \\
\text { dihasilkannya kurang akurat. }\end{array}$ & $\begin{array}{l}\text { Dibutuhkan sistem informasi yang dapat } \\
\text { memuat informasi dengan lengkap, } \\
\text { detail/terperinci, agar informasi yang } \\
\text { dihasilkan lebih cepat dan memiliki } \\
\text { akurasi tinggi. }\end{array}$ \\
\hline & $\begin{array}{l}\text { Membutuhkan biaya kertas non } \\
\text { paperless) untuk mencetak hasil } \\
\text { laporan data kebudayaannya. }\end{array}$ & $\begin{array}{l}\text { Tidak memerlukan biaya kertas } \\
\text { paperless) dan karena berbasis Web } \\
\text { maka sistem informasi data kebudayaan } \\
\text { ini dapat dengan mudah diakses. }\end{array}$ \\
\hline
\end{tabular}




\begin{tabular}{|c|l|l|}
\hline Control & $\begin{array}{l}\text { Keamanan sistem masih belum } \\
\text { terjaga dengan baik, rawan hilang, } \\
\text { dan masih belum optimal. }\end{array}$ & $\begin{array}{l}\text { Dengan adanya sistem database, dari segi } \\
\text { keamanan akan terjaga dengan baik dan } \\
\text { menjadikan data sudah terintegrasi } \\
\text { dengan optimal. }\end{array}$ \\
\hline \multirow{3}{*}{ Efficiency } & $\begin{array}{l}\text { Kurang efisien disaat mencari data } \\
\text { kebudayaannya karena sistemnya } \\
\text { manual dan memerlukan banyak } \\
\text { waktu untuk searching data. }\end{array}$ & $\begin{array}{l}\text { Dengan adanya sistem informasi berbasis } \\
\text { web dapat mempercepat pencarian data, } \\
\text { hal ini karena terdapat fitur Search yang } \\
\text { sudah terfilter dengan baik. }\end{array}$ \\
\hline \multirow{5}{*}{ Service } & $\begin{array}{l}\text { Pada sistem yang berjalan saat ini } \\
\text { mengenai proses penginputan, } \\
\text { update maupun saat pencarian data } \\
\text { masih mengalami banyak } \\
\text { kekurangan. }\end{array}$ & $\begin{array}{l}\text { Dengan sistem berbasis web ini sangat } \\
\text { fleksibel, cepat dan user friendly, } \\
\text { sehinga dapat mempermudah pada } \\
\text { proses pendataannya. }\end{array}$ \\
\hline
\end{tabular}

\subsection{Metode Perancangan Sistem}

Design System Methods pada penelitian ini banyak menggunakan tools aplikasi yang saling mendukung, seperti penggunaan Sublime Text, Visual Paradigm untuk diagram Unified Modeling Language (UML), XAMPP, MySQL, Google Chrome dan yang terpenting penggunaan PHP powerful yakni Framework CodeIgniter yang diusung sebagai jargon pada penelitian ini.

\subsection{Metode Pengujian Sistem}

Metode pengujian Sistem pada penelitian ini menggunakan pengujian Black Box yang dipaparkan pada tabel 2 dibawah ini :

a. Login Aplikasi

Tabel 2. Login Aplikasi

\begin{tabular}{|c|c|c|c|c|c|}
\hline No & $\begin{array}{l}\text { Skenario } \\
\text { Pengujian }\end{array}$ & Test Case & $\begin{array}{l}\text { Hasil Yang } \\
\text { Diharapkan }\end{array}$ & $\begin{array}{c}\text { Hasil } \\
\text { Pengujian }\end{array}$ & Keterangan \\
\hline 1 & $\begin{array}{l}\text { Mengosongkan } \\
\text { semua kolom } \\
\text { username dan } \\
\text { password }\end{array}$ & 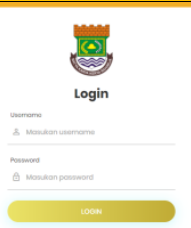 & $\begin{array}{l}\text { Sistem akan } \\
\text { menolak dan } \\
\text { tidak akan dapat } \\
\text { login }\end{array}$ & 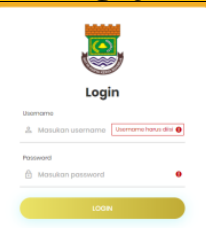 & Valid \\
\hline 2 & $\begin{array}{l}\text { Apabila salah } \\
\text { memasukkan } \\
\text { username dan } \\
\text { password }\end{array}$ & $\begin{array}{r}\text { login } \\
-\quad 0 \\
-\end{array}$ & $\begin{array}{l}\text { Sistem akan } \\
\text { menolak dan } \\
\text { menampilkan } \\
\text { pesan gagal }\end{array}$ & $\frac{\sqrt{\text { login }}}{-=}$ & Valid \\
\hline 3 & $\begin{array}{l}\text { Apabila username } \\
\text { dan password } \\
\text { benar }\end{array}$ & $\begin{array}{r}\text { login } \\
-\quad- \\
\end{array}$ & $\begin{array}{l}\text { Sistem berhasil } \\
\text { login dan masuk } \\
\text { kedalam } \\
\text { dashboard }\end{array}$ & secoss & Valid \\
\hline
\end{tabular}


b. Testing Aplikasi

\begin{tabular}{|c|c|c|c|c|c|}
\hline No & $\begin{array}{c}\text { Skenario } \\
\text { Pengujian }\end{array}$ & Test Case & $\begin{array}{l}\text { Hasil Yang } \\
\text { Diharapkan }\end{array}$ & $\begin{array}{c}\text { Hasil } \\
\text { Pengujian }\end{array}$ & Keterangan \\
\hline 1 & $\begin{array}{l}\text { Mengosongkan } \\
\text { semua kolom field } \\
\text { saat ingin input } \\
\text { data }\end{array}$ & $\begin{array}{l}E- \\
E- \\
E \\
E\end{array}$ & $\begin{array}{l}\text { Sistem akan } \\
\text { menolak dan } \\
\text { menampilkan } \\
\text { pesan bahwa } \\
\text { field harus diisi }\end{array}$ & 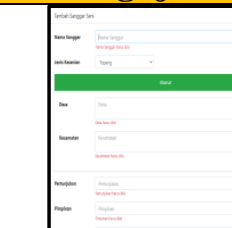 & Valid \\
\hline 2 & $\begin{array}{l}\text { Apabila admin } \\
\text { ingin menginput } \\
\text { data staf sebagai } \\
\text { user dengan } \\
\text { username yang } \\
\text { sama }\end{array}$ & 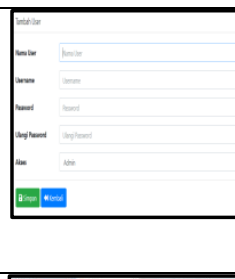 & $\begin{array}{l}\text { Sistem akan } \\
\text { menolak dan } \\
\text { menampilkan } \\
\text { pesan bahwa } \\
\text { username sudah } \\
\text { ada }\end{array}$ & 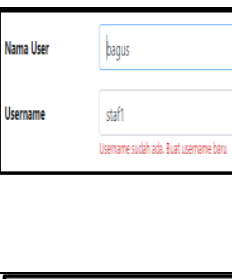 & Valid \\
\hline 3 & $\begin{array}{l}\text { Apabila } \text { user ingin } \\
\text { mengakses } \\
\text { halaman } \text { admin } \\
\text { melalui } u r l\end{array}$ & $\frac{}{\int_{21}^{12}-y^{23}-}$ & $\begin{array}{l}\text { Sistem akan } \\
\text { menolak dan } \\
\text { menampilkan } \\
\text { pesan bahwa hak } \\
\text { akses tidak } \\
\text { diijinkan }\end{array}$ & 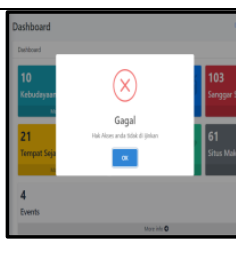 & Valid \\
\hline 4 & $\begin{array}{l}\text { Apabila salah satu } \\
\text { kolom field tidak } \\
\text { terisi pada saat } \\
\text { input data }\end{array}$ & 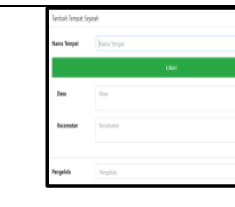 & $\begin{array}{l}\text { Sistem akan } \\
\text { menolak karena } \\
\text { kolom field } \\
\text { harus terisi }\end{array}$ & 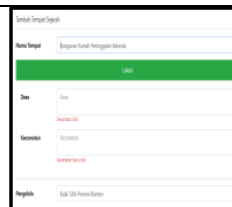 & Valid \\
\hline 5 & $\begin{array}{l}\text { Apabila saat input } \\
\text { data seluruh field } \\
\text { sudah terisi }\end{array}$ & $\begin{array}{l}E \\
- \\
- \\
= \\
z\end{array}$ & $\begin{array}{l}\text { Sistem akan } \\
\text { menampilkan } \\
\text { pesan sukses } \\
\text { yang artinya } \\
\text { data telah } \\
\text { berhasil diinput }\end{array}$ & 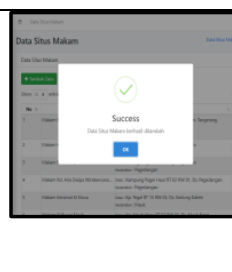 & Valid \\
\hline
\end{tabular}

\section{PEMBAHASAN}

Pada pembahasan penelitian ini, penggambaran analisanya menggunakan Use Case diagram, Activity diagram, Sequence Diagram dan Class Diagram, seperti dibawah ini :

\subsection{Use Case Diagram Sistem yang diusulkan}




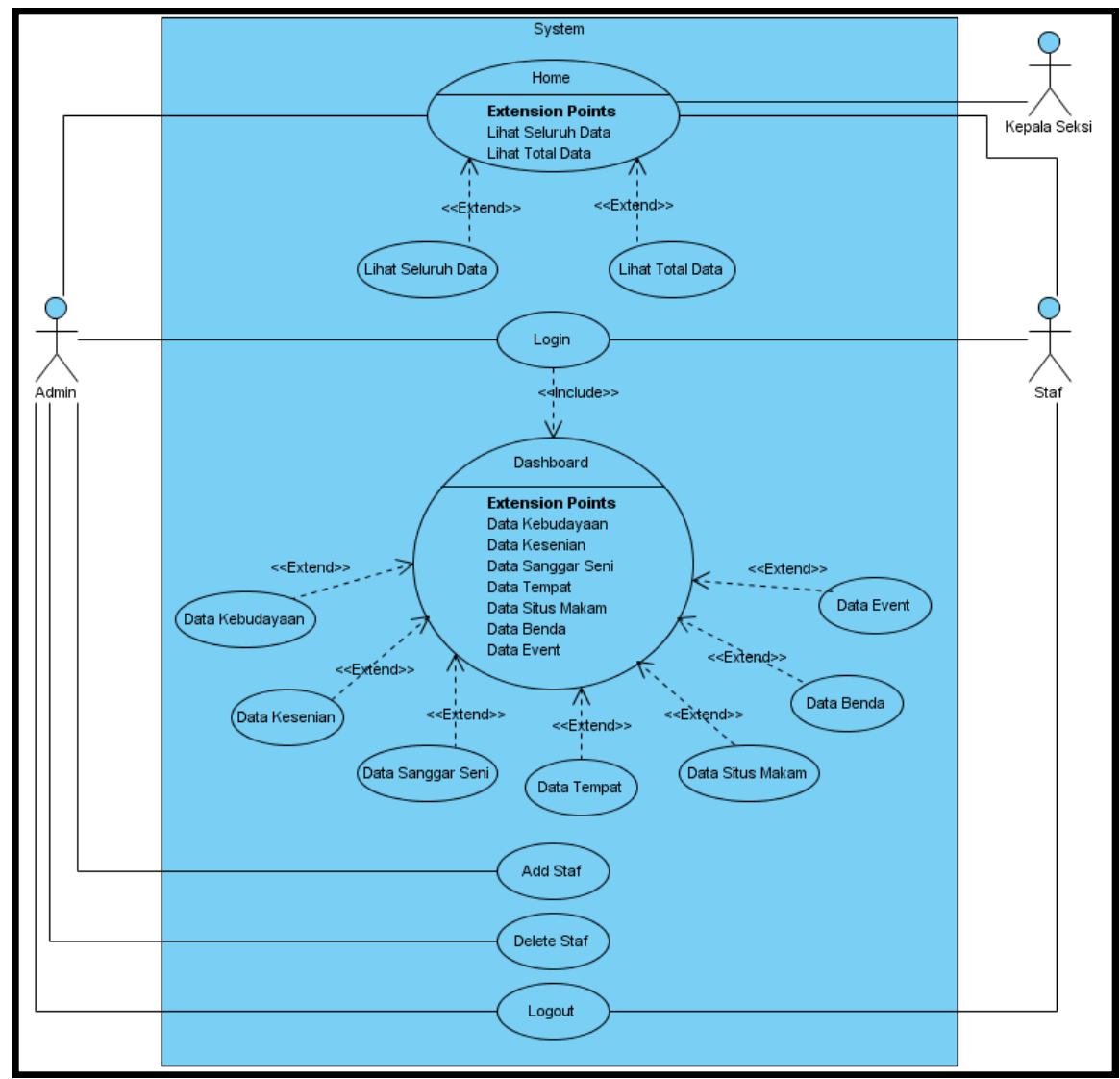

Gambar 1. Activity Diagram Sistem yang diusulkan

\subsection{Activity Diagram Sistem yang diusulkan}

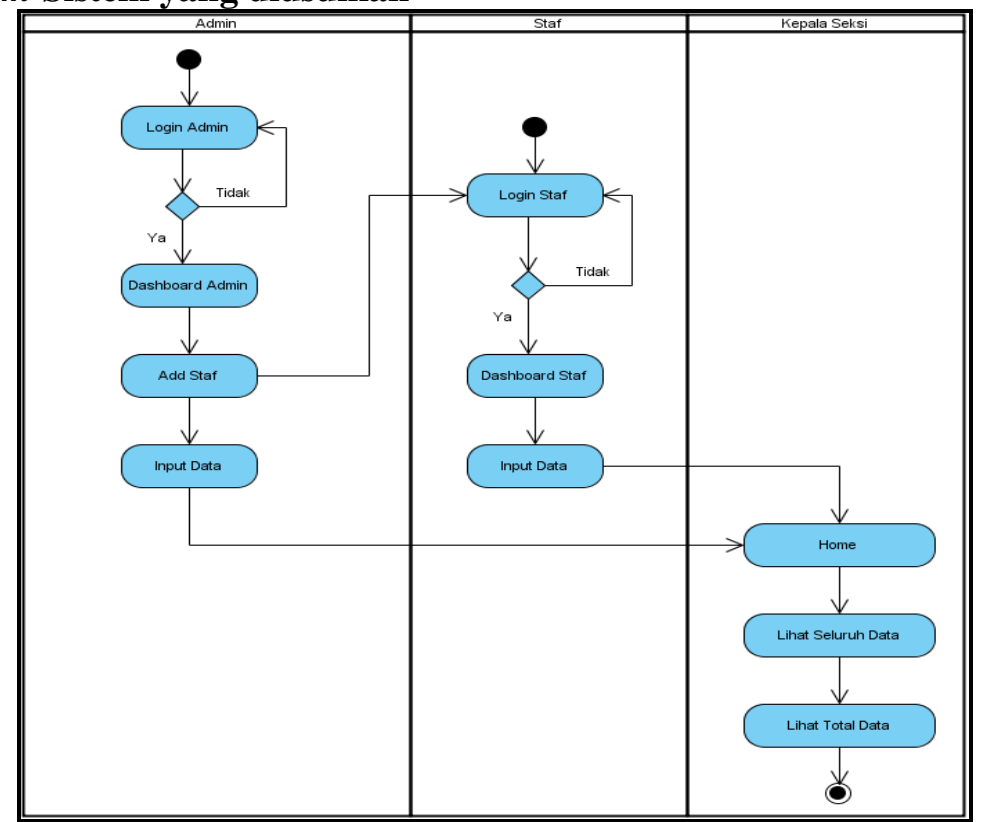

Gambar 2. Activity Diagram Sistem yang diusulkan

Pada Activity Diagram Sistem yang diusulkan, terdapat :

1. Terdapat 2 (dua) Initial Node untuk mengawali sistem.

2. Terdapat 10 (sepuluh) Action State untuk kegiatan/aktivitas yang dilakukan.

3. Terdapat 2 (dua) Decision Node, untuk keputusan Ya atau Tidak. 
4. Terdapat 1 (satu) Final Node untuk mengakhiri sistem.

\subsection{Sequence Diagram Sistem yang diusulkan}

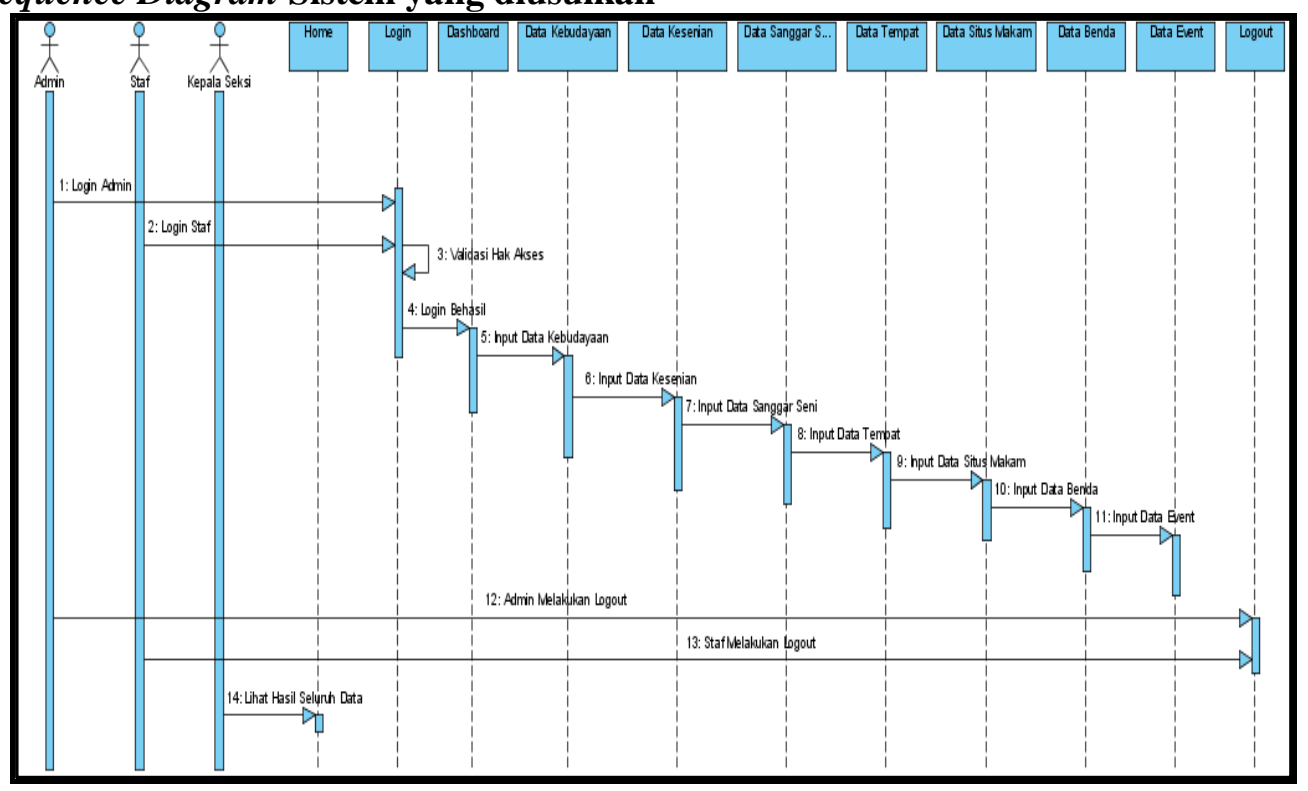

Gambar 3. Sequence Diagram Sistem yang diusulkan

Pada Sequence Diagram Sistem yang diusulkan, terdapat :

1. Terdapat 11 (sebelas) Lifeline untuk berbagai jenis data pada Web sistem informasi data kebudayaan

2. Terdapat 3 (tiga) Actor yang connecting dan menjalankan kegiatan ini.

3. Terdapat 14 (empat belas) Message yang merupakan aktivitas yang saling berhubungan satu dengan yang lainnya.

\subsection{Class Diagram}

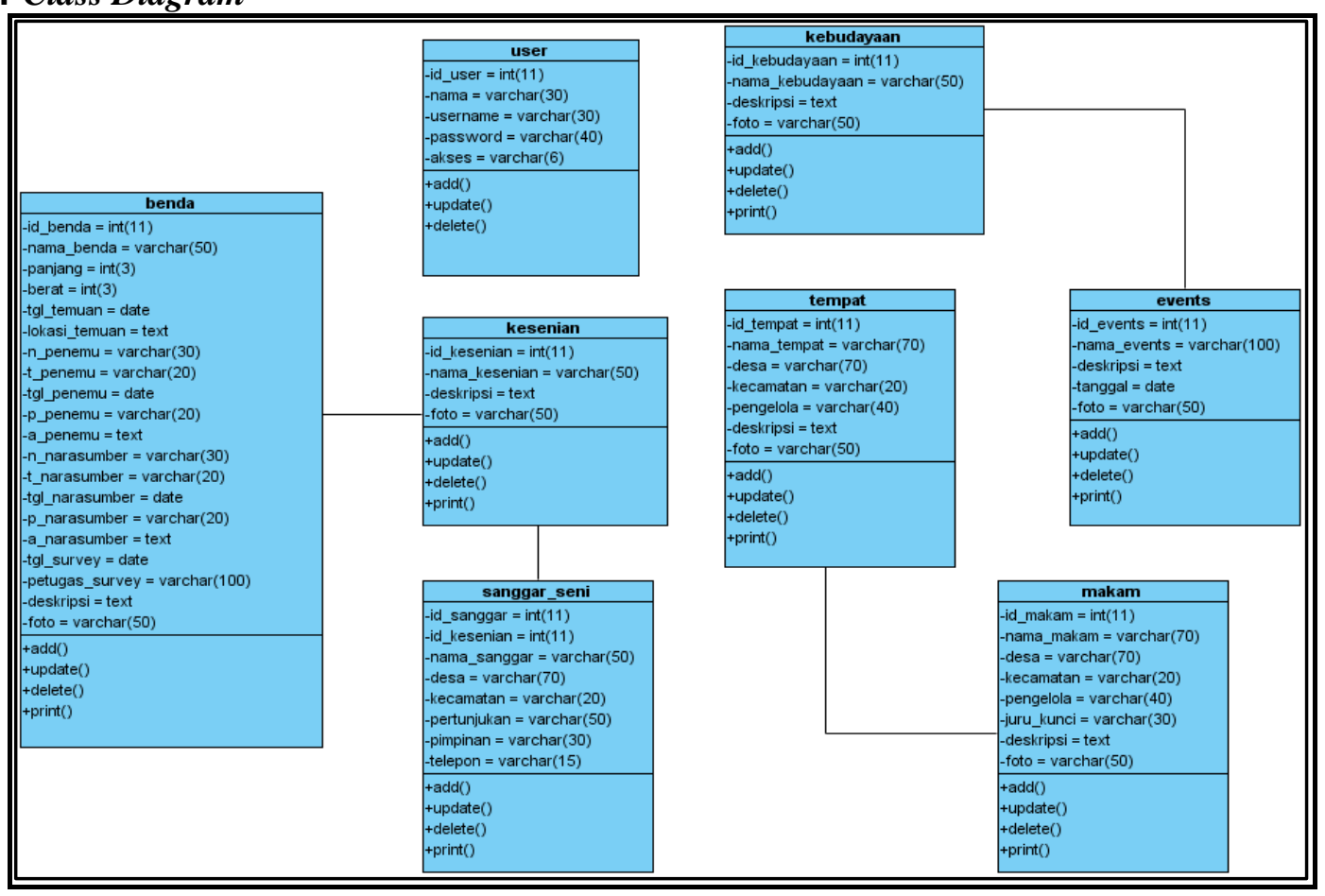

Gambar 4. Class Diagram Sistem yang diusulkan 


\subsection{Rancangan Program}

Berikut ini merupakan tampilan rancangan program dari sistem informasi data kebudayaan yang dibuat pada sistem usulan, yaitu sebagai berikut :

1. Halaman Login

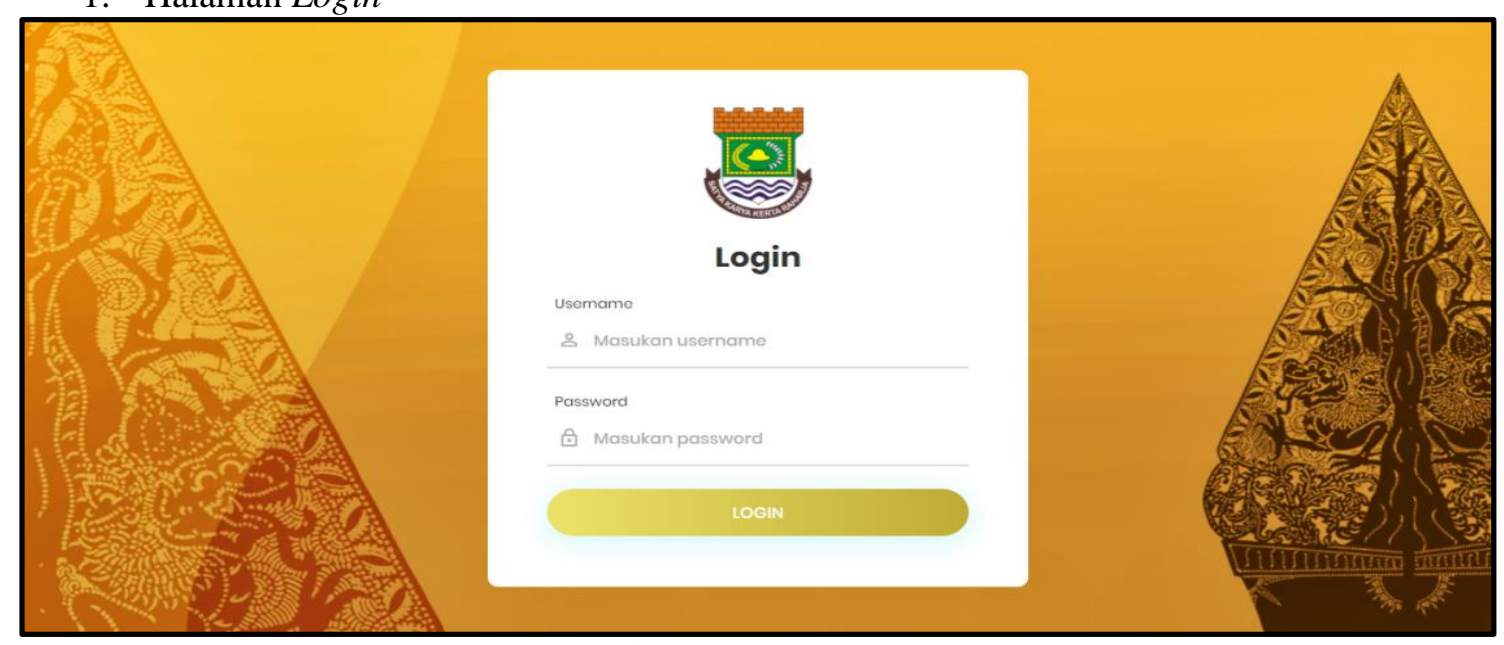

Gambar 5. Halaman Login

Pada halaman login, user bisa memasukan username dan password sesuai akses yang telah diberikan.

2. Halaman Dashboard Admin

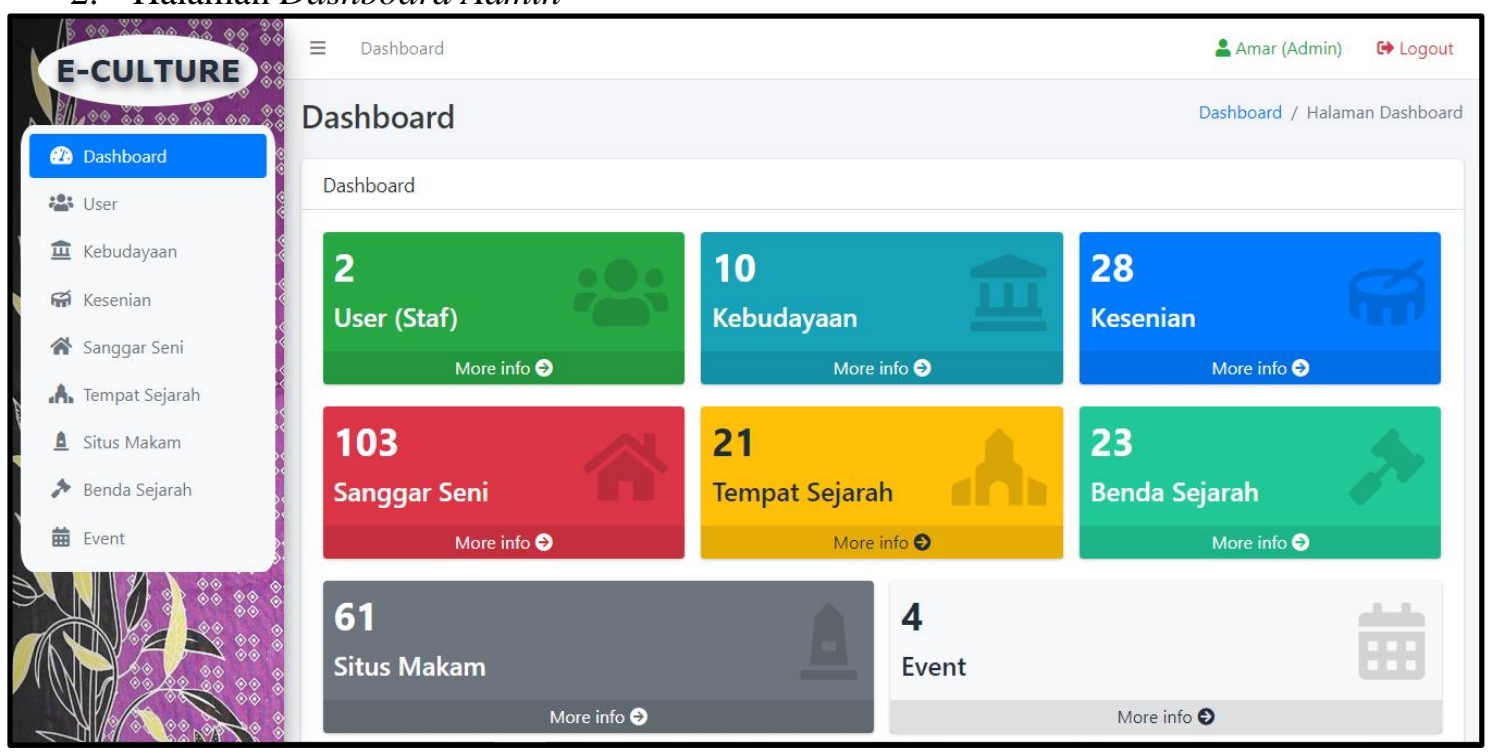

Gambar 6. Halaman Dashboard Admin

Berikut adalah halaman dashboard admin yang dapat melihat total dari keseluruhan data yang telah diinput. 
3. Halaman List Data Tempat Sejarah

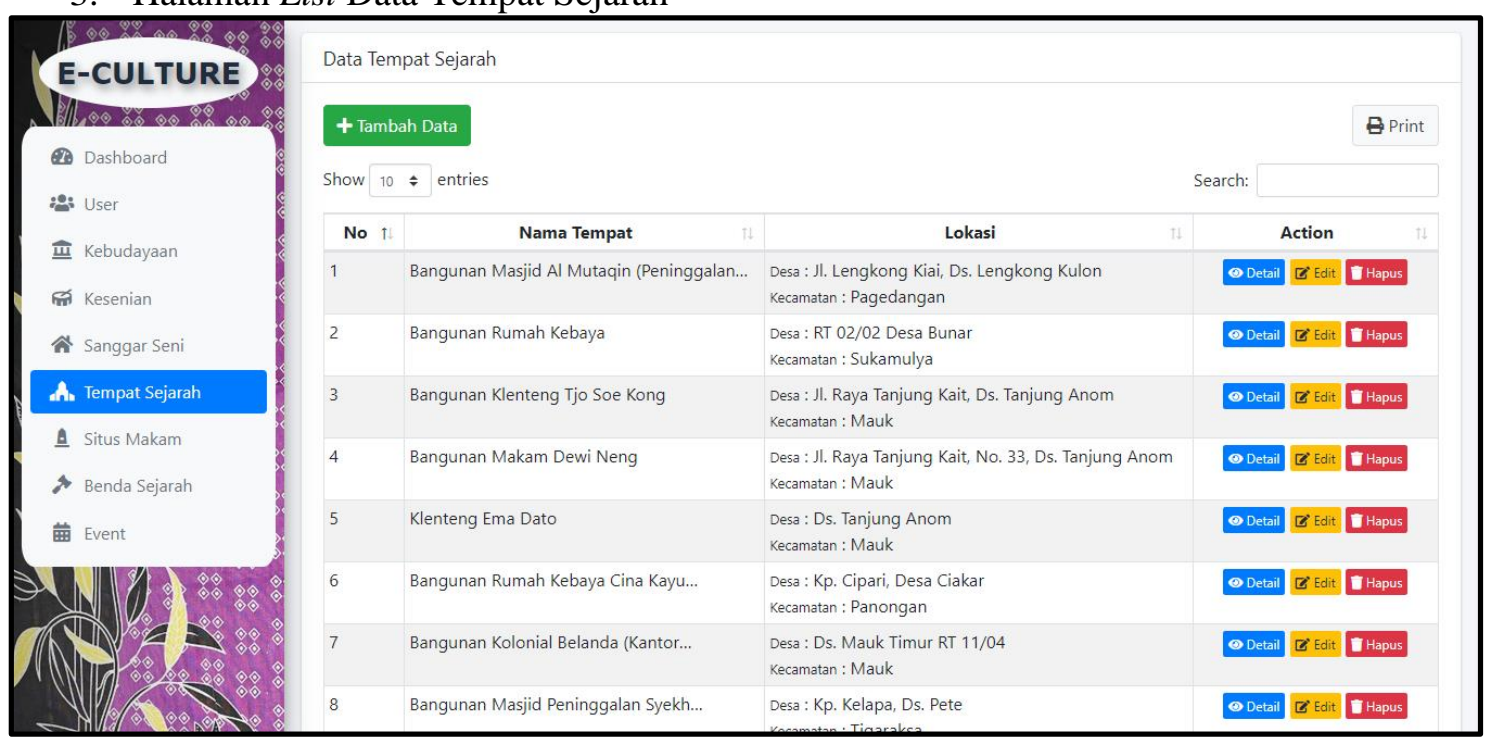

Gambar 7. Halaman List Data Tempat Sejarah

Berikut adalah halaman list data tempat sejarah, yang dapat melihat dari keseluruhan data, dan terdapat beberapa opsi seperti tambah data, detail, edit, print, maupun hapus data, terdapat juga fitur search untuk mencari data yang diperlukan.

4. Halaman Tambah Data Tempat Sejarah

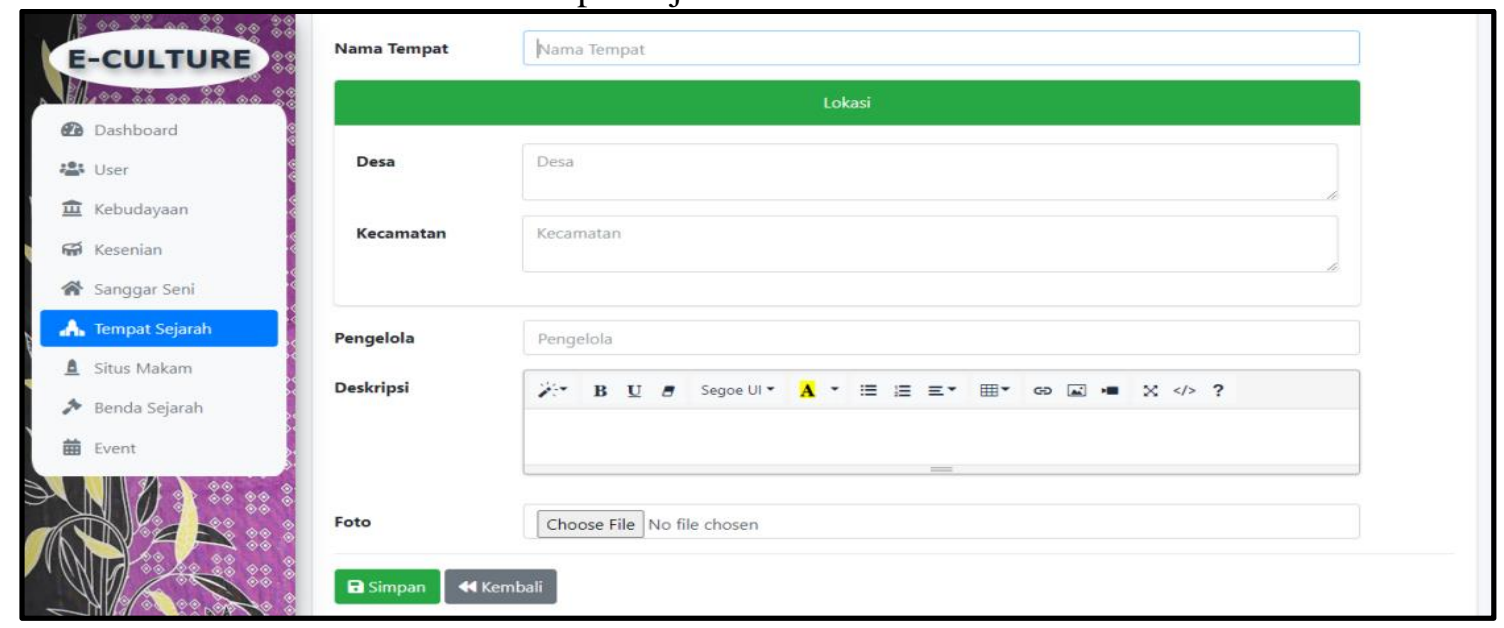

Gambar 8. Halaman Tambah Data Tempat Sejarah

Berikut adalah halaman tambah data tempat sejarah, dan terdapat beberapa field yang harus diisi didalam form tersebut yang selanjutnya akan diinput oleh admin maupun staf yang telah diberi akses. 
5. Halaman List Data Benda Sejarah

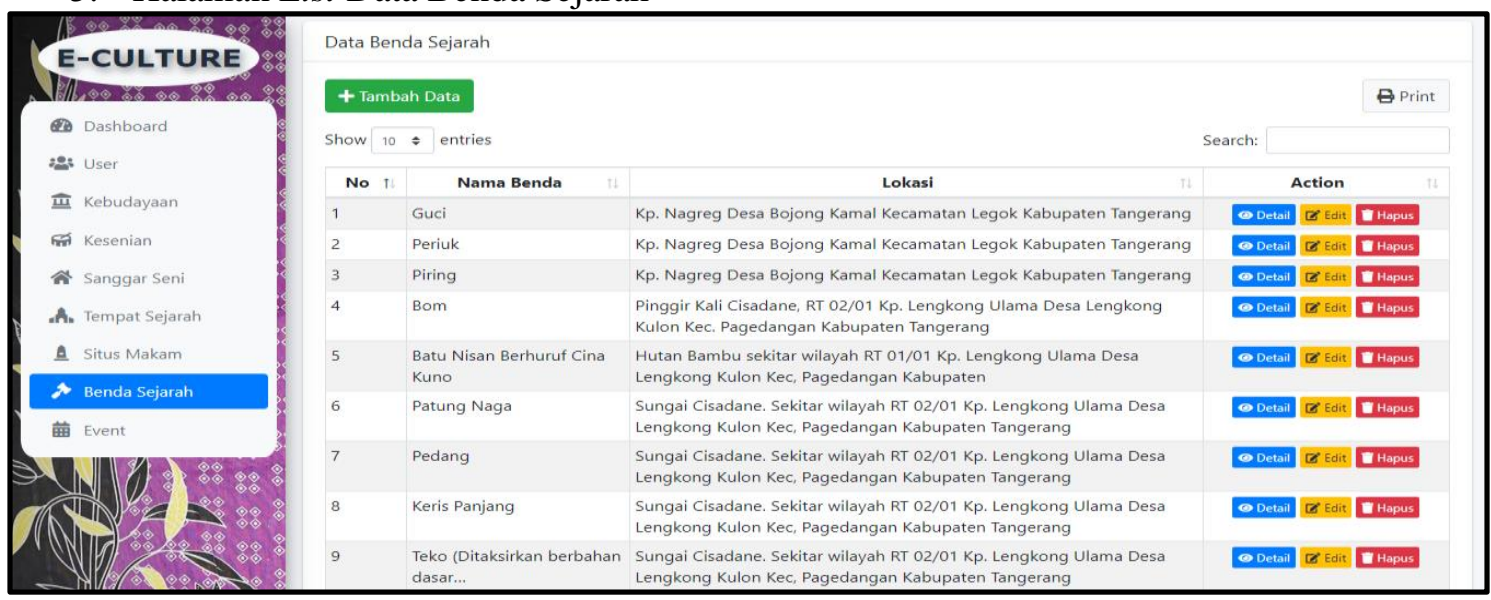

Gambar 9. Halaman List Data Benda Sejarah

Berikut adalah halaman list data benda sejarah, yang dapat melihat dari keseluruhan data, dan terdapat beberapa opsi seperti tambah data, detail, edit, print, maupun hapus data, terdapat juga fitur search untuk mencari data yang diperlukan.

6. Halaman Tambah Data Benda Sejarah

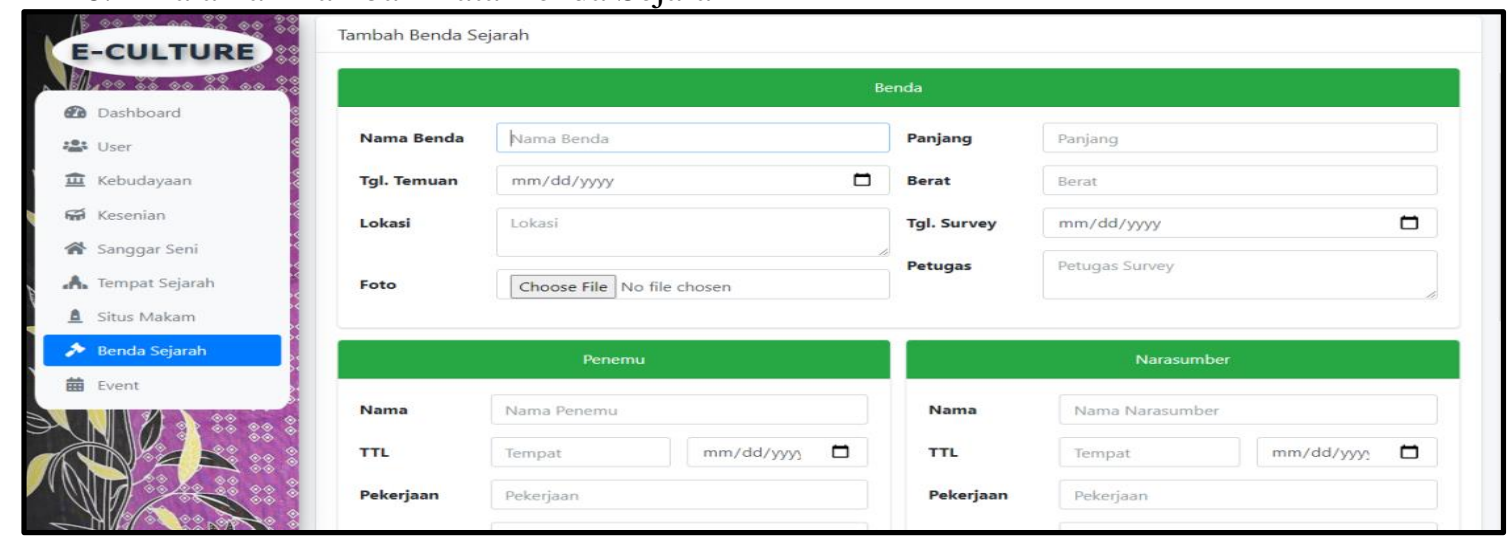

Gambar 10. Halaman Tambah Data Benda Sejarah

Berikut adalah halaman tambah data benda sejarah, dan terdapat beberapa field yang harus diisi didalam form tersebut yang selanjutnya akan diinput oleh admin maupun staf yang telah diberi akses.

7. Tampilan Cetak Keseluruhan Data

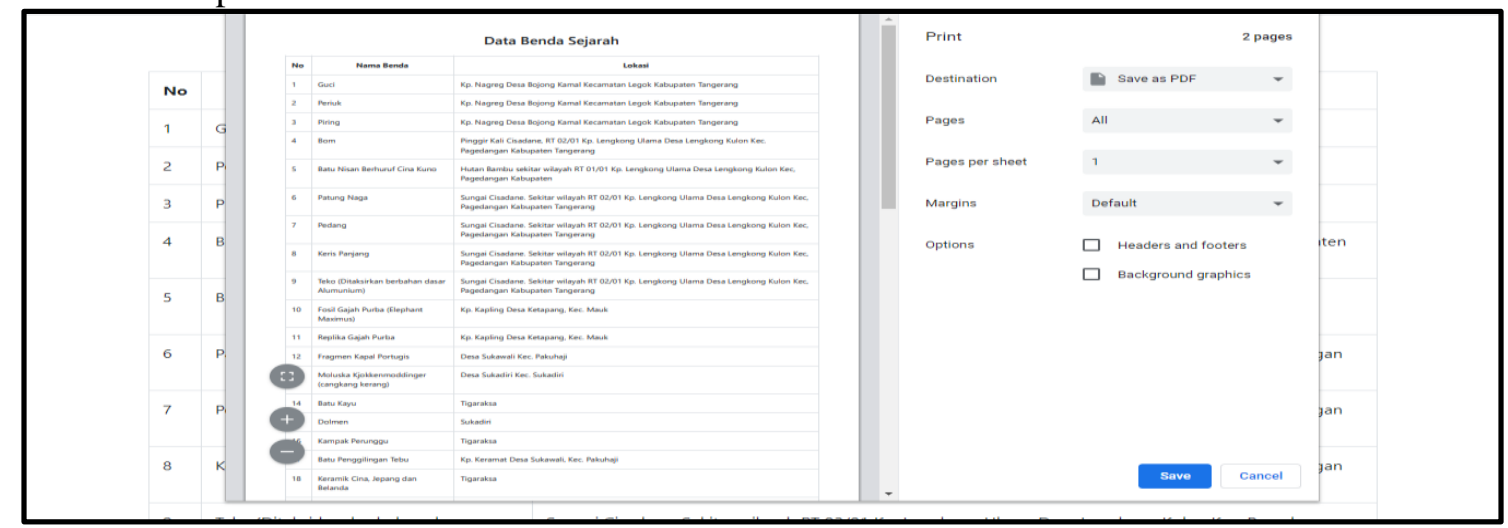

Gambar 11. Tampilan Cetak Keseluruhan Data 
Berikut adalah tampilan saat mencetak keseluruhan data yang telah diinput, bisa disimpan dengan format pdf maupun word.

8. Tampilan Cetak Detail Data

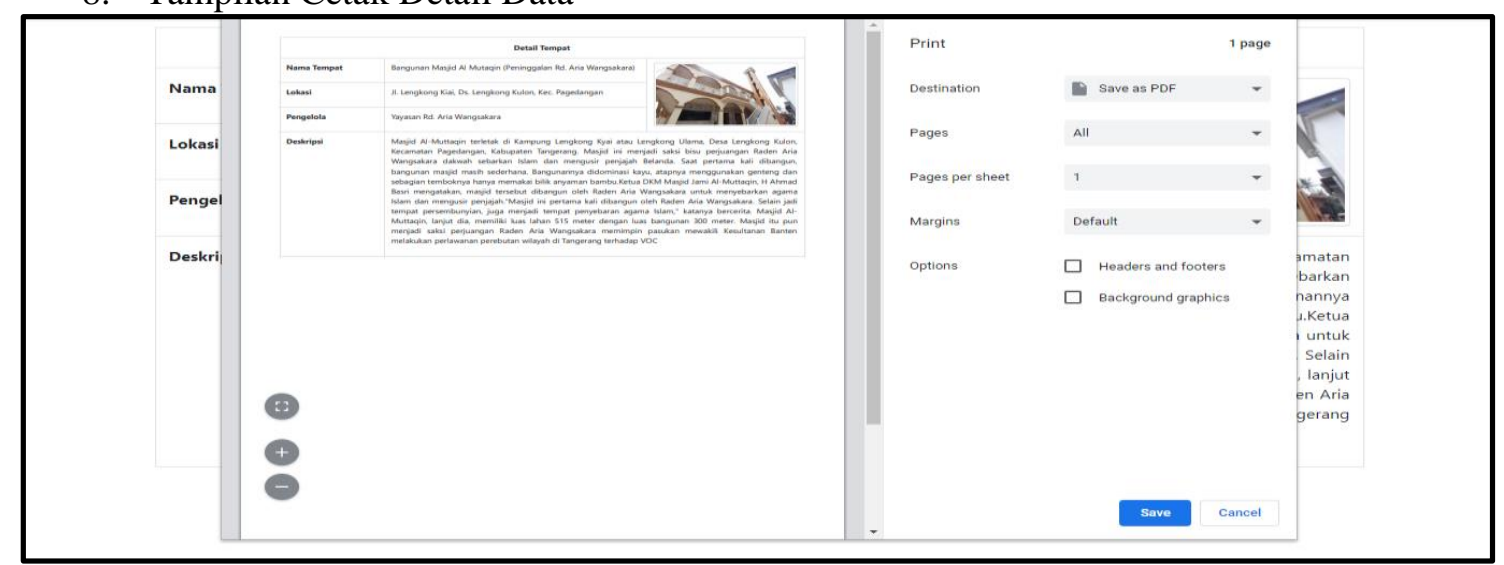

Gambar 12. Tampilan Cetak Detail Data

Berikut adalah tampilan saat mencetak detail dari data yang akan dipilih dan sesuai dari isi data tersebut.

9. Halaman Menu Home

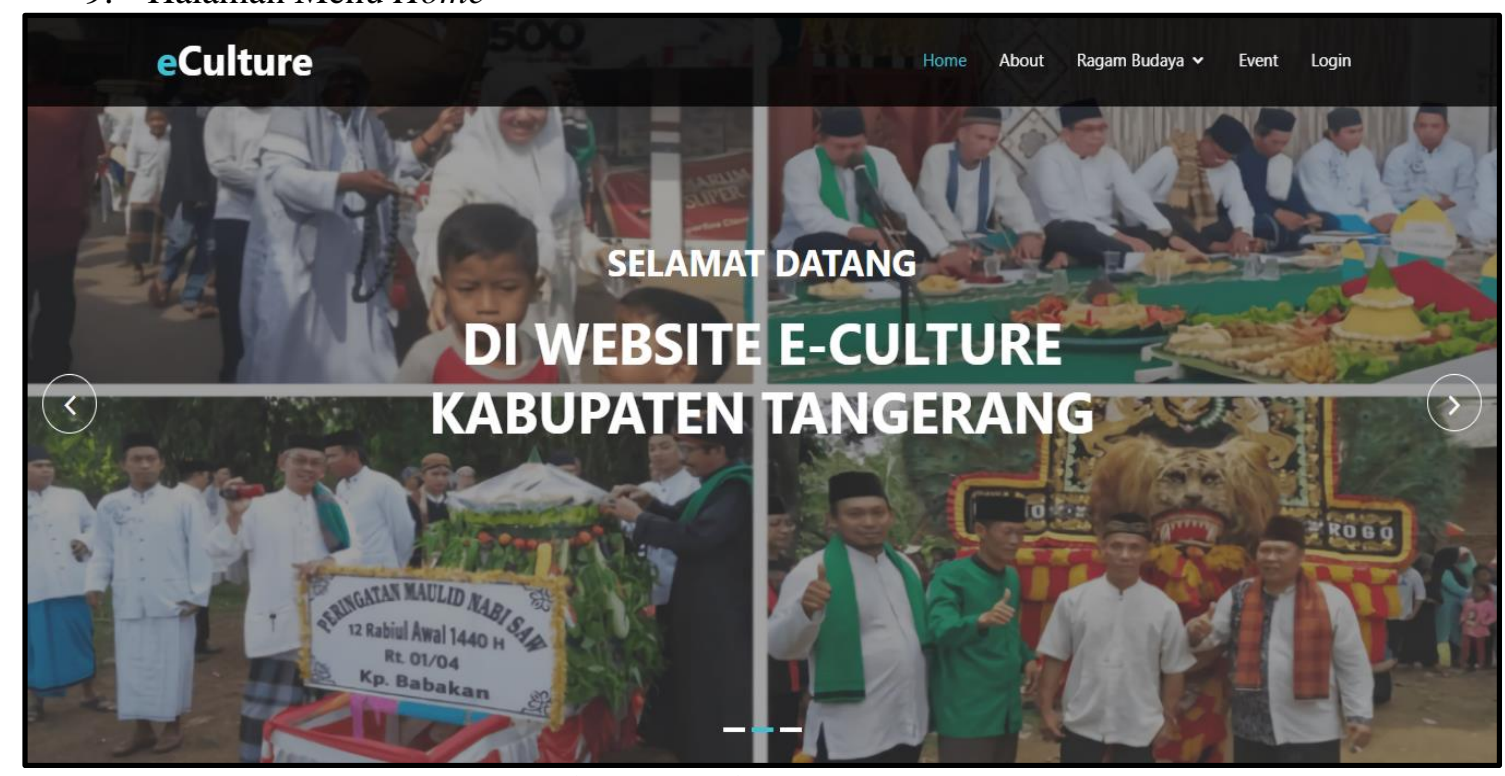

Gambar 13. Halaman Menu Home

Berikut adalah halaman menu home, halaman pertama saat mengakses website tersebut. 
10. Halaman List Kebudayaan Pada Menu Home

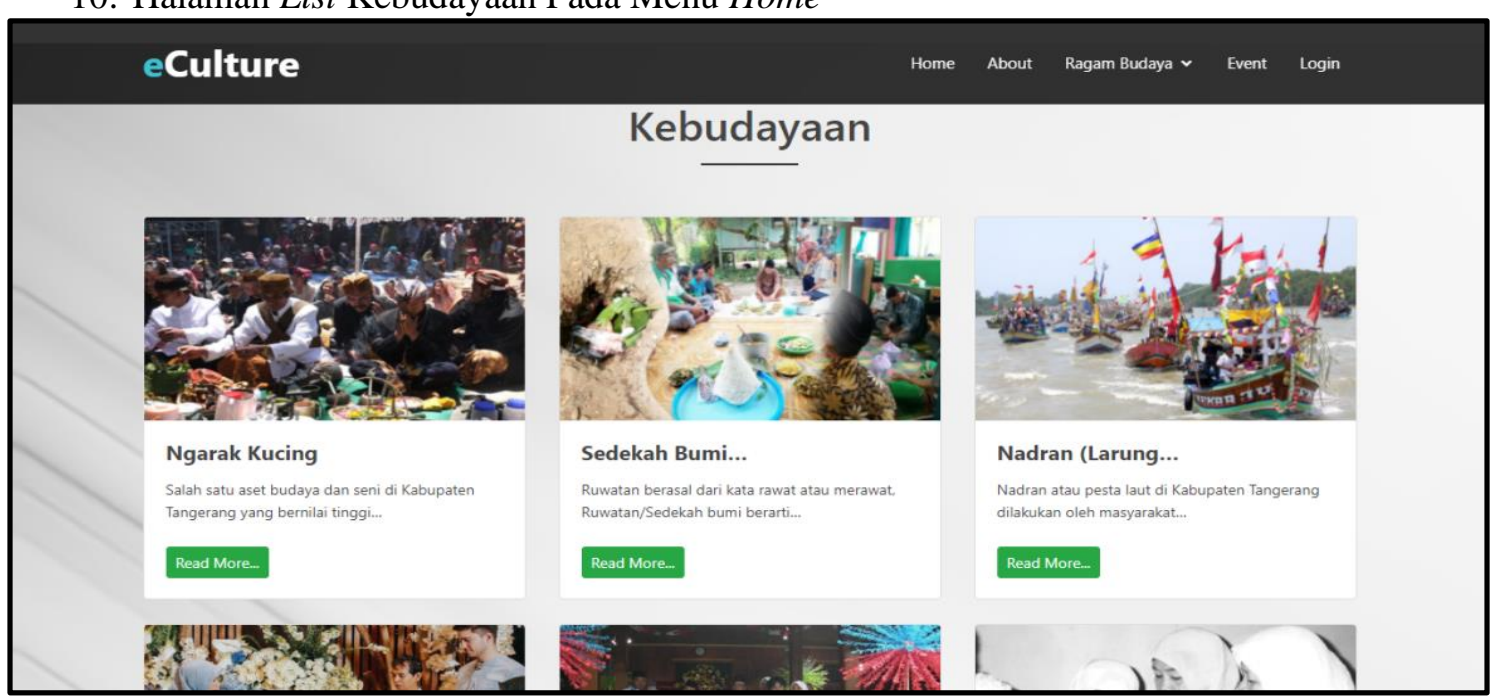

Gambar 14. Halaman List Kebudayaan Pada Menu Home

Berikut adalah halaman list kebudayaan pada menu home, dan terdapat beberapa isi dari hasil data yang telah diinputkan.

\section{KESIMPULAN}

Sistem informasi yang ada saat ini untuk data kebudayaan pada instansi pemerintahan khususnya pada Disporabudpar Kabupaten Tangerang dinilai masih manual dan kurang optimal sehingga memiliki beberapa kendala pada saat proses penyimpanan data-datanya dan masih rawan hilang karena data masih disimpan dalam dokumen biasa, selain itu juga masih belum efektif dari segi keamanannya. Untuk itulah penting untuk diterapkannya hasil penelitian ini yang berupa sistem informasi data kebudayaan yang berguna dan bermanfaat untuk instansi pemerintahan yang mengoptimalkan penggunaan framework CodeIgniter yang powerful.

\section{SARAN}

Disarankan agar hasil penelitian ini dapat digunakan dengan baik untuk dapat memberikan manfaat yang besar bagi instansi pemerintahan terutama pada Disporabudpar Kabupaten Tangerang di dalam mengelola data-data kebudayaan daerah yang merupakan aset penting kebudayaan suatu daerah yang bernilai seni tinggi.

\section{DAFTAR PUSTAKA}

[1] Rahwanto, E., \& Sudaryono, S. (2020). Perancangan Sistem Informasi Penjualan Berbasis Web pada PT. Inter Aneka Plasindo. PANDAWA, 2(3), 335-358.

[2] Gunadi, F., \& Widianto, S. R. (2020, February). Perbandingan Data Warehouse Cloud Computing Menggunakan Konvensional Berbasis Kriptografi. In Seminar Nasional Teknologi Komputer \& Sains (SAINTEKS) (Vol. 1, No. 1, pp. 69-73).

[3] Novitasari, N., Nufus, A. B., \& Mahendradi, R. M. (2020, October). PENGARUH KEBUDAYAAN MASYARAKAT TERHADAP PENGAMBILAN KEPUTUSAN 
PEREMPUAN MENJADI BURUH MIGRAN INDONESIA (STUDI KASUS DI DESA BANARAN KECAMATAN GRABAG KABUPATEN MAGELANG). In SENASTER" Seminar Nasional Riset Teknologi Terapan" (Vol. 1, No. 1).

[4] Ruktami, F. (2018). Sistem Informasi Pengolahan Data Kebudayaan Minangkabau Berbasis Web.

[5] Christian, A. (2018). Perancangan Sistem Informasi Website Seni Budaya Prabumulih pada Dinas Pendidikan dan Kebudayaan Kota Prabumulih. InfoTekJar: Jurnal Nasional Informatika dan Teknologi Jaringan, 3(1), 81-84.

[6] Manuho, R., Rindengan, Y. D., \& Sinsuw, A. A. (2018). Aplikasi Sistem Informasi ECulture Kabupaten SITARO Berbasis Web. Jurnal Teknik Informatika, 13(2). 